by Mr. Starr, a young American, and paterited in this country under the title of "King's Patent Electric Light," specification enrolled March 25, 1846. An account of it, with drawings, may be found in the Mechanic's Maoazine, A rril 25, 1846, p. 312. To this are appended some editorial remarks in which the novelty of the invention was at that date disputed. Those who care to follow the subject further may find a letter of mine replying to this editorial criticism in the Mechanic's Magazine of May 9, I 846, p. 348 .

I constructed a large battery and otherwise assisted Mr. Starr in his experiments on this light. The "wick," as Mr. Munro aptly calls it, was a stick of gas retort carbon, like that pictured (NATURE, p. 423), excepting that it was affixed to supports of porcelain in order to remedy the fracture which occurred to our first apparatus in which the carbon stick was rigidly held in metallic forceps. Thus the improvement of M. Kosloff was also anticipated.

The lamp-glass was a thick barometer tube about thirty-six inches long, with its upper end blown out to form a large bulb or expanded chamber. The carbon and its, connections were mounted in this with a platinum wire passing through and sealed into the upper closed and expanded end of the tube.

The whole of the tube was then filled with mercury and inverted in a reservoir, and thus the carbon stick, \&c., were left in a Torricellian vacuum. The current was passed by connecting the electrodes of the battery with the mercury (into which a wire from the lower end of the carbon dipped) and with the upper platinum wire respectively. A beautiful steady light was produced accompanied with a very curious result which at the time we could not explain, viz., a fall of the mercury to a bout half its barometrical height and the formation within the tube of an atmosphere containing carbonic acid.

I have now little doubt that this was due to the combustion of some of the carbon by means of the oxygen occluded withis itself.

In pointing out this anticipation of M. Lodighin's invention I do not assume or suppose that any piracy has been perpetrated. It is one of those repetitions of the same idea which are of such common occurrence and which cost the re-inventor and his friends a vast amount of trouhle and expense that might be saved if they knew what had been done before.

I may add that the result of our battery experiments was to convince $\mathrm{Mr}$. Starr that a magneto-electric arrangement should be used as the source of power in electric illumination; and that he died suddenly in Birmingham in 1846 , while constructing a magnetic battery with a new armature which, theoretically, appeared a great improvement on those used at that date. Of its practical merits I am unable to speak.

Twickenham, September I 8 W. MattieU Williams

\section{Serpula Parallela}

Two or three years ago I read somewhere that Serpula parallela of $\mathrm{M}^{*} \mathrm{C}$ y is probably a vitreous sponge. Can any of your readers give me a reference for this? I wish to give the authority for this happy suggestion to which Mr. Young and I referred last year.

Glasgow University, September I9 JOHN YOUNG

\section{HYDROGRAPHIC SURVEY OF THE BALTIC}

$\mathrm{W}$

E learn from the Stockholm Nya Dagligt Allehanda that during the month of July last a hydrographical survey of the Baltic was carried out by two vessels belonging to the Swedish navy, which were placed for this purpose at the disposal of the Swedish Royal Academy of Sciences for a month. A grant of about $550 l$. is intended to cover the expenses of three such expeditions. The whole of the Baltic, from a line drawn from Arendal to Jutland to the head of the Gulf of Bothnia and from the Swedish coast on the one side to the Finnish, Russian, German, Danish, and Norwegian on the other, was examined for temperature and salinity along thirty-four lines, measuring together more than 23,000 English miles, and including 200 stations. At every such station the temperature and salinity of the sea water were ascertained at the surface and at several different depths down to the bottom, about $\mathbf{1} ; 800$ different determinations of temperature having been made and a corresponding number of samples of water obtained. The nature of the bottom has also been ascertained by instruments which brought up samples not only from the surface of the bottom, but also from a variable depth, occasionally several feet, under it. The plan of this survey, which is said to be the most complete that has yet been made for its special objects, the determination of the salinity and temperature, was drawn up and carried out by Prof. F. L. Ekman. New instruments for taking samples of sea-water at different depths were employed, and as the temperature of the water did not undergo any perceptible alteration during the time required for getting it to the surface, for every sample that was obtained, the temperature of the depth from which it was raised was ascertained simultaneously, without any great loss of time. The survey shows the Baltic and the Gulf of Bothria to consist of three strata, differing greatly in temperature, and often very sharply defined, viz., an upper stratum, which is warmed during the summer by the heat of the sun to a pretty high temperature, a lower, in which the cold of winter still prevailed to a great extent, and under the latter still another of a somewhat higher temperature than the intermediate stratum, the third stratum being of great thickness where the depth was considerable. In the Gulf of Bothnia, as in Skagerack and Kattegat, on the other hand, the temperature diminished steadily in proportion to the depth, as is commonly the case in the ocean. The uppermost summer-warm stratum of water was found to be of variable thickness at different places in the Baltic; at some it was scarcely perceptible at the period of observation. This and other peculiarities will probably be explained in the course of the working out of the observations which is now proceeding.

\section{OUR ASTRONOMICAL COLUMN}

The Saturnian Satellite Hyperion.--The following ephemeris of this satellite for the next period of absence of moonlight is founded upon the elements calculated by Prof. Asaph Hall, of Washington, from his measures in 1875 . Though limited to dates when Saturn may be observed while the moon is absent, probably her presence, except when very near the planet, is less an impediment to viewing so faint an object than the unavoidable proximity of the planet itself.

At Ioh. Greenwich M.T.

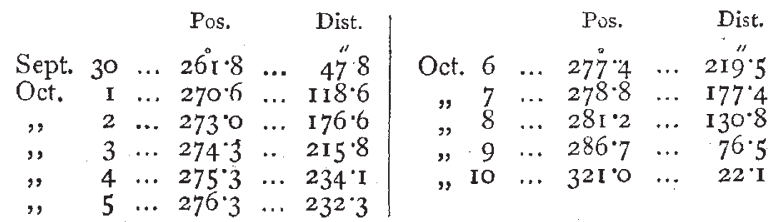

An ephemeris of the five inner satellites of Saturn, by Mr. Marth, appears in No. 2,154 of the Astronomische Nachrichten. It is elaborately compiled, but this the first portion, extending to September 2o, only reached this country on the date of its expiration. It is to be regretted that a work of this interest involving so much care and trouble in its preparation, should not have been in the hands of astronomers earlier; it is not the first instance of unfortunate delay in the publication of communications of immediate utility in this periodical of late.

THE NEW COMET (1877, IV.).-A first approximation to the orbit of the faint comet discovered at Marseilles on the 14th inst. calculated by Mr. Hind upon M. Coggia's Qbservation on that date, and observations at Leipsic by 
Prof. Bruhns, and Strasburg by Prof. Winnecke on the 17 th and 18 th respectively, gives the following elements:-

Perihelion Passage, September 6.4104 Greenwich M.T.

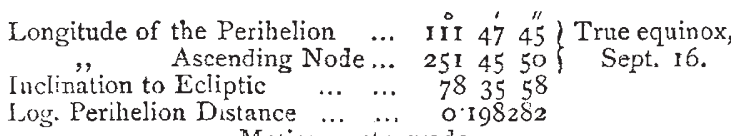
Motion-retrograde.

The middle observation is represented with errors of $+7^{\prime \prime}$ in longitude and $-2^{\prime \prime}$ in latitude.

A few computed positions are subjoined, but they are to be regarded only as rough ones:-

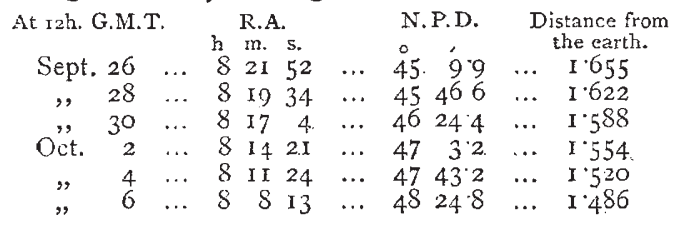

According to the above orbit the comet will remain visible for many weeks, approaching the earth, though ieceding from the sun, as it descends to the node; the intensity of light, however, is not likely to much exceed twice its actual amount. The elements do not present a striking similarity to those of any comet previcusly computed.

It is the fourth comet newly discovered in the present year, the others having been found (I) by M. Borrelly, February 8 ; (2) by Prof. Winnecke, April 5 ; and (3) by Mr. Swift on April II. D'Arrest's comet of short period, which has been observed on its fourth return, is to be added to these, and as this comet is still in a position to be observed with our larger instruments a few places are subjoined :-

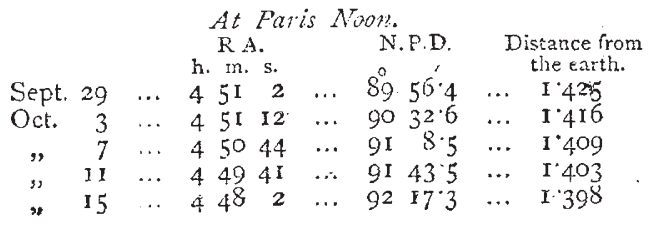

\section{FAMINES AND SHIPWRECKS}

$T$ HE following letter from Dr. Balfour Stewart appeared in the Times of Saturday last :-

I have read with much interest your various articles on Dr. Hunter's researches into the Madras rainfall and the possible connection of famines with sun-spots, and I perceive from the letter in your columns of yesterday by Mr. Henry Jeula, of Lloyd's, that he has found most shipwrecks during periods of maximum solar activity.

I consider it a fortunate thing for science that the physics of the sun are now judged of sufficient importance to occupy the attention of the leading journal, inasmuch as the duty of the man of science is rather quietly to continue investigating than to endeavour to force prominently before the public the results of his work.

It has been recognised now for several years that in this particular case of shipwreck as in others the study of solar physics must ultimately lead to results of national importance. In illustration of this I may quote from a lecture delivered by Mr. Lockyer in October, 1872 ("Solar Physics," p. 423) :-

"Mr. Meldrum, a distinguished meteorologist, who lives, not in the temperate zones of the earth, where the meteorological conditions are irregular, but in the torrid zone, where regular meteorological phenomena, and among them cyclones, abound, tells us that it is no longer correct to merely associate cyclones with the tropics. He tells us that the whole question of cyclones is a question of solar activity, and that if we write down in one column the number of cyclones in any given year and in another column the number of sunspots in any given year, there will be a strict relation between them-many sun-spots, many hurricanes; few sun-spots, few hurricanes. Only this morning I have received a letter from Dr. Stewart, who tells me that Mr. Meldrum has since found that what is true of the storms which devastate the Indian Ocean is true of the storms which devastate the West Indies ; and, on referring to the storms of the Indian Ocean, Mr. Meldrum points out that at those years where we have been quietly mapping the sun-spot maxima the harbours were filled with wrecks, vessels coming in disabled from every part of the great Indian Ocean. Now that surely is something worth considering, because, if we can manage to get at these things, to associate them in some way with solar activity, so that there can be no mistake about it, the power of prediction-that power which would be the most useful one in meteorology, if we could only get at it-would be within cur grasp."

I will, with your permission, make a few remarks on the present position of the problem and on the scientific policy for the future which this position naturally suggests. In the first place, what are the facts? Without the sun, the atmosphere of our earth would be as dead and inactive as a cotton mill without fire in its boiler. As in the case of such a mill, the work done will depend upon the strength of the furnace fire, so that if the fire be variable the work will vary with it. As regards our earth, we know, to begin with, of two distinct periods of meteorological variation. The one of these is due to the change of apparent position of the sun in the heavens caused by the earth's rotation, and its length is one day. The other is due to a similar change caused by the earth's revolution, and its length is one year. If the sun were intrinsically constant we should not be justifed in looking for any other variation (unless we attribute some infiuence to the moon); but if the sun be variable in its power we are led to look for a corresponding variation in terrestrial activity. Now we know that the sun is a variable factor. At certain periods his disc is absolutely free from spots, while at others it is studded with these curious objects. On these last occasions we have other lines of evidence, which lead us to believe in the intense activity of the sun, or, in the forcible language once used by the late Sir J. Herschel to myself, the solar pot seems then to be boiling very rapidly. If we are to reason by analogy at all, the terrestrial pot must follow the solar one, and occurrences denoting a deficiency of energy, such as periodical famines, depending on local failures of vegetable food, will be grouped round years of deficient solar activity, while other occurrences, depending on great energy; such as cyclones and shipwrecks, will rather follow the periods of maximum solar activity. I have taken two instances (famines and cyclones), but I might have taken others of a more recondite nature, such as the phenomena of terrestrial magnetism, concerning which I believe I am justified in stating that those who work at this branch of science are satisfied that a decided effect has been traced to the variability of the sun as a cause.

It is quite right that men of science who are pursuing other branches of inquiry, that statesmen who have to utilise the teachings of science for the benefit of nations, and, permit me to add, editors of powerful journals like your own, should wish that the proof might be of a more absolutely convincing kind than that which has satisfied the workers that they are on the right way. At present the problem has not been pursued on a sufficiently large scale or in a sufficient number of places. In fine, if the attack is to be continued, the skirmishers should give way to heavy guns, and these should be brought to bear without delay now that the point of attack is known.

There are, of course, two ways of treating the problem. The evidence may be pronounced insufficient and the 